\title{
Combining concept maps and interviews to produce representations of personal professional theories in higher vocational education: effects of order and vocational domain
}

Citation for published version (APA):

Van den Bogaart, A. C. M., Schaap, H., Hummel, H. G. K., \& Kirschner, P. A. (2017). Combining concept maps and interviews to produce representations of personal professional theories in higher vocational education: effects of order and vocational domain. Instructional Science, 45(3), 359-376. https://doi.org/10.1007/s11251017-9407-3

DOI:

10.1007/s11251-017-9407-3

Document status and date:

Published: 01/01/2017

Document Version:

Peer reviewed version

Please check the document version of this publication:

- A submitted manuscript is the version of the article upon submission and before peer-review. There can be important differences between the submitted version and the official published version of record. People interested in the research are advised to contact the author for the final version of the publication, or visit the DOI to the publisher's website.

- The final author version and the galley proof are versions of the publication after peer review.

- The final published version features the final layout of the paper including the volume, issue and page numbers.

Link to publication

\section{General rights}

Copyright and moral rights for the publications made accessible in the public portal are retained by the authors and/or other copyright owners and it is a condition of accessing publications that users recognise and abide by the legal requirements associated with these rights.

- Users may download and print one copy of any publication from the public portal for the purpose of private study or research.

- You may not further distribute the material or use it for any profit-making activity or commercial gain

- You may freely distribute the URL identifying the publication in the public portal.

If the publication is distributed under the terms of Article 25fa of the Dutch Copyright Act, indicated by the "Taverne" license above, please follow below link for the End User Agreement:

https://www.ou.nl/taverne-agreement

Take down policy

If you believe that this document breaches copyright please contact us at:

pure-support@ou.nl

providing details and we will investigate your claim.

Downloaded from https://research.ou.nl/ on date: 26 Apr. 2023 
Combining Concept Maps and Interviews to Produce Representations of Personal Professional Theories in Higher Vocational Education: Effects of Order and Vocational Domain

\author{
Antoine C.M. van den Bogaart ${ }^{1}$, Harmen Schaap ${ }^{2}$, \\ Hans G. K. Hummel ${ }^{3} \&$ Paul A. Kirschner ${ }^{3}$ \\ ${ }^{1}$ NHL University of Applied science, The Netherlands \\ ${ }^{2}$ Radboud University, The Netherlands \\ ${ }^{3}$ Open University of the Netherlands
}

\begin{abstract}
Author Note
Correspondence concerning this article should be addressed to Antoine C. M. van den Bogaart, NHL University of Applied science, Rengerslaan 10, 8917 DD Leeuwarden, The Netherlands, E-mail: a.c.m.van.den.bogaart@nhl.nl
\end{abstract}

Keywords: personal professional theories, interviews, concept maps, vocational education, accountancy, teacher training. 
Abstract

This article is about the use of personal professional theories (PPTs) in Dutch higher vocational education. PPTs are internalised bodies of formal and practical knowledge and convictions, professionals use to direct their behaviour. With the aid of high-quality representations of students' PPTs teachers can access, monitor, and support the professional development of students. Two qualitatively equivalent techniques for representing PPTs are (computer-supported) concept mapping and interviewing. This article reports on a study of the effects of combining these techniques to determine whether (1) this results in higher quality representations and (2), if so, whether technique order will make a difference. The study was conducted in two very different vocational domains: accountancy with 29 participants and teacher education with 20 participants. The results of a counterbalanced quasi-experiment with two factors (i.e. domain and order) show in both domains that combining the techniques improves quality but order does not matter. This order independence has practical importance as the computer-supported analysis of a student generated concept map and subsequently discussing the results with the student, fosters learning and fits in educational practice well. 


\section{Introduction}

A personal professional theory (PPT) is a construct which denotes the knowledge schema stored in long term memory that is used by a professional as a reference base for both acting as a professional and further professionalization (Schaap, De Bruijn, Van der Schaaf, \& Kirschner, 2009). Knowledge of PPTs is important in vocational education (Van den Bogaart, Bilderbeek, Schaap, Hummel, \& Kirschner, 2016). If the main features of a student's PPT could be made visible, they provide teachers information on the student's view of the profession (s)he is learning, because important aspects such as its priorities, awareness of professional issues, cohesion and the connection between experience and theory become explicit. This could support teachers in discussing its quality with the student as a form of formative assessment and designing future learning experiences for the student. For instance, in teacher education it is important that a student teacher realises that his/her content knowledge, its didactics and classroom management must be at the service of the development of children. If in a student's PPT the development of children is only weakly connected with such items, this could give rise to organise a traineeship focused at the educational guidance of children.

Separate parts of PPTs are frequently assessed in educational practice by means of tests, papers, reports, etc. However, chances are more global issues such as the aforementioned stay unnoticed (Ben-Peretz, 2011). A well-known method to acquire information on complete PPTs is the assessment of portfolios. But this method is laborious and therefore it is usually applied occasionally (Tillema \& Smith, 2007). In search for other methods to uncover and assess PPTs, Schaap, De Bruijn, Van der Schaaf, Baartman, and Kirschner (2011) used semi-structured interviews, log files and concept maps. To evaluate PPTs, they defined four qualities: concreteness, a PPT's ability to support carrying out professional actions; specificity, a PPT's uniqueness for a certain profession; complexity, the degree of content interconnection in the PPT; and richness, the degree of diversity of concepts in the PPT. Triangulation of the data obtained by the interviews, log files and concept maps showed that these qualities could be reliably and validly determined, though differences in sensitivity were found between different techniques. The log file analysis appeared to be the least sensitive as it produced the lowest levels for all four qualities. Semi-structured interviews scored highest on complexity, concreteness and specificity. Concept maps obtained the highest scores on richness (Schaap et al., 2011). However, since all three methods were laborious to execute as well, they were not easily usable in every day educational practice, either as an aid for teaching or for assessment. 
Van den Bogaart et al. (2016) refined the concept map technique using a computer program (BrainWeaver®), which supports construction and assessment of annotated, open concept maps. Two typical concept maps are shown in Figure 1 and Figure 2. The students who constructed the maps in an hour were a student teacher of English and an accountancy student. For the sake of clearness the annotations (i.e., examples and clarifications) of only one element (i.e., the concepts maintaining order and administrative organisation) are shown in each concept map.

\section{*** INSERT FIGURE 1 ABOUT HERE *** *** INSERT FIGURE 2 ABOUT HERE ***}

To make computer-supported assessment of the four qualities possible, each quality was operationalised as explained in the method section. A two-year quasi-experiment with 47 student teachers half of which were interviewed and half drew a concept map, showed that the computer program made the construction and assessment of concept maps as representations of PPTs expedient in every day practice of education. An experienced assessor (i.e., teacher trainer) supported by BrainWeaver® could assess the concept map of a PPT in 20 minutes and this evaluation is reliable: different assessments of the same map resulted in similar values of the four qualities. Both students and assessors commented that the technique was pleasant to apply and provided valuable information on students' professional development. The refined technique yielded qualities similar to those of interviews, although the content of the representations differed (e.g., statements on professional values were seldom found in concept maps but were often found in interviews).

A question raised in that research was whether these results on the power and equivalence of the techniques would be generalizable to other vocational domains. A second question was whether combining interviews and concept maps would result in higher quality representations. PPTs are large collections of personal professional knowledge, skills and even attitudes. Results from the field of knowledge engineering show that it is improbable that a single knowledge elicitation technique could reveal them completely (Burton, Shadbolt, Rugg, \& Hedgecock, 1989; Milton, Clarke, \& Shadbolt, 2006). A third and final question was whether the order of combining both techniques makes a difference.

This study, thus, has three goals namely to: (1) compare the qualities of PPT representations produced with the refined concept map technique with those based on interviews in a domain other than teacher education; (2) determine whether combining concept maps with semi-structured 
interviews leads to higher quality representations of PPTs than each technique alone; and (3) determine whether the order of use yields different quality representations.

\section{Theoretical Background}

Effects of choice of vocational domain on the qualities of PPTs

In vocational education students develop their PPT by internalizing both the semantic and procedural knowledge of their future profession gained in their courses and the workplace knowledge gained through reflection in and on action (Lave \& Wenger, 1991; Schön, 1983) during periods of workplace learning (Pedersen, 2007). Although in the Netherlands all conventional vocational programs in higher education roughly have the same structure (Ten Dam, Van Hout, Terlouw, \& Willems, 2004), a closer look reveals that substantial differences between learning experiences might exist even within a domain. These could be caused by differences between institutions due to differences in the staff, institutional policy, culture, perspectives on learning, and the pedagogies employed (Bijker, Van der Klink, \& Boshuizen, 2010), or differences within institutions due to differing opportunities for workplace learning (Guile \& Griffiths, 2001). This variety is likely to lead to a large diversity of PPTs within the same domain (Van den Bogaart et al., 2016). Besides this diversity within domains, the characteristics of different domains may also cause differences due to the specific nature of the domain. This research deals with two vastly different domains, namely accountancy and teacher education. According to Hines (1989), the accounting profession can be characterised as a procedural skill domain with fixed rules. When preparing for a task, the accountant weighs different approaches, chooses the one that seems most appropriate and then acts accordingly (Schön, 1983). By reflecting on action (i.e., considering possible explanations and ways to proceed along with the outcomes of the choice made), standards develop, first in the form of high level causal networks and then as scripts (Vaatstra, 1996). These scripts can be elicited and represented as protocols by knowledge engineers and even converted into algorithms for software as, for instance, in the case of software for producing annual accounts.

In teaching, this procedural character is less strong (Hargreaves, 2000) and the behaviours exhibited are more heuristic than algorithmic. When preparing a lesson, a teacher contemplates the state of affairs in his/her class to determine the best way to proceed. Through experience, the teacher develops ‘design patterns' (Kolfschoten, Lukosch, Verbraeck, Valentin, \& De Vreede, 2010); general 
modes of behaviour to be applied when teaching in specific circumstances such as: restoring order in a classroom, de-escalate a conflict with a pupil and discussing a subject with a group of pupils. However, the possibilities to realise such design patterns in a specific classroom are limited (Waks, 1999).

Teachers know that planning a lesson is one thing, but conducting the lesson as planned is another. Due to the important situational and interpersonal nature of teaching, the lesson can take a complete other course than planned. This is sometimes described as the chaotic nature of teaching (Buitink, 1998; Cvetek, 2008).

Another characteristic difference between accountancy and teaching, possibly relevant for PPTs, is the twofold nature of teaching knowledge as contrasted with accountancy. As one teaches, one teaches a subject, so a teacher has to have both knowledge of teaching (i.e., pedagogy) and of the subject (s)he teaches (i.e., domain-specific knowledge) (Furedi, 2009; Shulman, 1987). To cover the large diversity of knowledge elements and experiences teachers might need more abstract and general building blocks of their PPT's. This is very different from accountancy where the protocols used are applicable in a limited number of specific situations (i.e., they are concrete and specific). A consequence of these differences might be that the concepts in the PPTs of accountancy students are more concrete and specific. In turn, tools that are good for explicating the PPTs in one domain might not work in another, dissimilar domain.

\section{Effects of techniques on representations}

Given the nature of a PPT, the power of a knowledge elicitation technique depends on its capability to elicit and represent: personal and communal professional values and beliefs (Pajares, 1992); encapsulated knowledge (Schmidt, \& Boshuizen, 1993), semantic knowledge (McCarthy, 1995), procedural and episodic knowledge (Ashcraft, 2006) and formal and underlying practical knowledge (Kondrat, 1992; Van Driel, Beijaard, \& Verloop, 2001).

For eliciting and representing professional values and beliefs, interviews are more suited than concept maps due to the interaction between interviewer and interviewee. If an interviewer succeeds in creating a safe climate, an interviewee may be willing to share personal, professional convictions, beliefs, motives and values (Barriball \& While, 1994). For eliciting encapsulated knowledge, semistructured interviews are also better due to the fact that interviewer probing offers the opportunity to elicit implicit knowledge (Barriball \& While, 1994). Due to their graphical nature and the use of concepts as labels denoting knowledge units, concept maps are often seen as models for organising 
semantic knowledge (Ruiz-Primo \& Shavelson, 1996). Both the meaning and the applicability of concepts in different contexts (Van Oers, 1987) are dependent of their relations with other concepts. This can be partially captured in the propositions uttered in interviews (Jonassen, 2006), but better in concept maps (Van den Bogaart et al., 2016). That is why concept maps are better suited than interviews to elicit and represent semantic knowledge. It is more difficult to capture elements of procedural and episodic knowledge in concept maps because such elements can illustrate more than one concept (Reif, 2010), which makes it difficult to unambiguously represent this in a concept map. This difficulty does not occur in interviews, so they are easier to use when capturing procedural and episodic knowledge (Jetter, 2006). Finally, regarding formal and underlying practical knowledge, Zanting, Verloop, and Vermunt (2003) showed that in the field of teacher education, concept maps are better able to elicit and represent reasons underlying teaching than semi-structured interviews. The reason they give is that in concept maps it is easy to relate concepts denoting practical knowledge such as classroom management to more theoretical concepts such as the theory of peer groups. On the other hand, interviews yielded more concrete information than concept mapping.

\section{***INSERT TABLE 1 ABOUT HERE***}

An overview of this comparison is given in Table 1. As both techniques have their strong and weak points, it is plausible that combining the two could generate higher quality representations of PPTs than either alone. In that case the equivalence of semi-structured interviews and the refined concept map technique found in Van den Bogaart et al. (2016), indicates that the strong and weak points of each technique may compensate each other.

Finally, the interaction between interviewer and interviewee leads to the question whether the order of interventions in a combined procedure matters. When someone is first interviewed about his/her PPT and is then asked to produce a concept map, the interview acts as a prompt for the production of the concept map. One could see the concept map as a concrete schematic representation of the interview. If someone is interviewed about a concept map of a PPT produced in an earlier stage, clarifications can be asked for on concepts represented as well as on relations between concepts.

\section{Research questions}

Based on the aforementioned, the following research questions are formulated:

1. How do the qualities obtained by the two different techniques compare in the domains of accountancy and teacher education? 
2. Does combining these techniques lead to higher quality representations in both domains than each technique alone?

3. Does the order of using both techniques in the two domains yield different quality representations?

To answer these questions an exploratory, quasi-experimental study was conducted.

\section{Method}

\section{Participants}

The study comprised 49 students at an institution for higher vocational education, a form of higher education in the Netherlands, which emphasises the world of work instead of theory and research which is emphasised by universities. For the domain of teacher education, 20 participants ( 5 male, 15 female, $M_{\text {age }}=23.1$ years, $S D=1.7$ ) were student teachers in the third year of their programme; 12 had the English language teaching as their subject, 6 had German as their subject and 2 French. For the domain of accountancy, 29 (16 male, 13 female, $M_{\text {age }}=23.9$ years, $S D=2.0$ ) were at the beginning of their fourth and last year. The student teachers had just finished a 10-week period (four days a week) of student teaching in secondary education. The accountancy students had finished a 6-month practice period in the second half of their third year.

Design

In a counter balanced design, students from both domains were divided into two groups for individual planning reasons. Two of these four groups, one with 10 student teachers and one with 14 accountancy students, were interviewed about their PPT first, and were then asked to construct a concept map of their PPT. This procedure is denoted as I-C. The other two groups with 10 student teachers and 15 accountancy students followed the reversed procedure, denoted as C-I. Each procedure resulted in two representations of the PPT for each participant; one based on the interview or the concept map produced first and one based on a combination of the interview and the concept map. This way four pairs of datasets were formed, each pair belonging to one of the four groups: accountancy-C-I, accountancy-I-C, teaching-C-I and teaching-I-C. For example, accountancy-C-I contains 1) the concept maps produced by the accountancy students before they were interviewed and 2) the combined representations (i.e., the original representation augmented by the interview). The answers given in this study to the three research questions are all based on these eight datasets.

Instrumentation: the construction of the first and combined representations 
A representation derived from a concept map is a disjoint collection of two kinds of sets (Van den Bogaart et al., 2016). Sets of the first kind are called theme-sets. Each theme-set represents a concept, with elements the annotations added to the concept. Sets of the second kind are called relation-sets. A concept can be connected with several relation-sets. Each relation-set represents a relation-arrow between the concepts and another concept, with elements the annotations added to the relation. Themesets and relations-sets are labelled according to the corresponding concepts and relations. This means that apart from the place of the focus, there is a 1:1-correspondence between concept maps and their representations.

A representation derived from an interview consists of the same two kinds of sets. Each theme-set contains all the utterances in an interview on a certain theme, such as classroom management in teaching and annual accounts in accountancy. Each relation-set contains all utterances explaining a certain relation between two theme-sets, for instance the relation between bookkeeping and annual accounts in accountancy. To make representations of interviews and concept maps comparable, the content analysis of each interview was directed by the concept map of the interviewee (Elo \& Kyngäs, 2008; Hsieh \& Shannon, 2005). This meant that the concept and relation labels of each concept map were used to label the theme-sets and relation-sets of the corresponding interview. Only when a theme or a relation occurred in an interview that did not occur in the corresponding concept map, a new label was introduced.

Like the representations of concept maps, the representations of interviews are also disjoint collections of sets with the exception of utterances containing episodic or procedural knowledge and referring to more than one theme, as explained earlier. These utterances are included in all the relevant theme-sets. For instance, the utterance “This class functions best when I let them work in groups and then offer these groups challenging problems to solve" could be included in three concepts: pedagogical approaches, challenging learning material and collaborative learning.

A combined representation contains the unions of all identically labelled theme-sets and relation-sets from an interview and concept map representation together with the unique theme-sets and relation-sets from each representation. This construction guaranteed in each procedure, I-C and C-I, the similarity in structure of the initial and the combined representations; both are disjoint collections of sets with the possible exception of fragments of episodic or procedural knowledge. Together with the 
correspondence in labels, this similarity made it possible to compare the qualities of both representations.

Instrumentation: the determination of the values for the qualities

The values of the four qualities can be calculated from a representation in the same way as from a concept map. In Van den Bogaart et al. (2016), this is done for concreteness in three steps. First, each element of each theme-set and relation-set, example or clarification, is evaluated as concrete or not by an assessor using a reference document with examples. Then the level of concreteness of each themeset is determined. A theme-set is considered to be 'more concrete' $=2$, if the set together with its connected relation-sets contain $\geq 4$ concrete elements; 'average concrete' $=1$, if they contain 2,3 concrete elements; and 'less concrete' $=0$ if they contain 0,1 concrete elements. Finally, the level of concreteness of the representation is calculated as the average of these numerical values, expressed as a percentage. The level of specificity is calculated in the same way. The level of complexity is also determined in the same way, but in this calculation also the numbers of relation-sets connected to theme-sets are taken into account. Table 2 and Table 3 show how assessors judged the concreteness, specificity and complexity of the annotations to the concepts maintaining order and administrative organisation from the concept maps in Figure 1 and Figure 2.

\section{*** INSERT TABLE 2 ABOUT HERE *** *** INSERT TABEL 3 ABOUT HERE ***}

For example, based on the definition of concreteness given in the introduction, an annotation is considered to be concrete if and only if the annotation gives an indication when/how to act. Based on the judgements, the concept maintaining order was scored more concrete (four concrete annotations), average specific (three specific annotations) and average complex (two complex annotations). (In reality, some scores for both concepts were higher because the annotations of the relevant relations (i.e., purpose, supports and directed to) were also taken into account.) On the basis of Table 3 and apart from the annotations of relations, the concept administrative organisation was scored more concrete, more specific and less complex. For the calculation of the fourth quality, richness, all examples of all theme sets have to be classified as belonging to one of six domains of knowledge: vocational field knowledge, organisational knowledge, knowledge of one's professional environment, target group knowledge, technical-instrumental knowledge and self-knowledge (Schaap et al., 2011). For example, the first annotation in Table 2 was judged as a proposition expressing target group knowledge, the 
second as a technical-instrumental statement. All annotations in Table 3 were judged as expressing technical-instrumental knowledge. The classifications can be transformed into percentages that expresses the level of richness using a formula explained in Van den Bogaart et al. (2016). A low percentage for richness is an indication that important aspects of a professional theory are missing or that some aspects are overrepresented. The construction procedure for combined representations and the determination procedures for the qualities guarantee that if a combined representation gets a higher quality value, this is caused by the fact that the combined representation contains more information relevant for the quality as compared with the initial representation.

\section{Materials}

The same materials were used as in Van den Bogaart et al. (2016). The protocol of the semi-structured interviews in the I-C-procedures allowed only questions asking for completion or clarification. In the

C-I-procedure, the questions in the interview referred to the concept map: asking for more examples of concepts in the concept map, explanations of relations between concepts, and new concepts, examples and relations. For constructing and assessing concept maps, the digital tool BrainWeaver® was used. As the tool offers the functionality to describe relations between concepts and to illustrate and clarify concepts by means of annotations, it was possible to insert episodic knowledge and professional values in the concept maps. The assessments of all the representations were supported by a reference document with: (1) lists of examples of the domains of knowledge from both professions and (2) descriptions of the four qualities and domain-specific examples of expressions of different qualities such as 'You have to speak English with your pupils' (not concrete) and 'In each lesson you may only converse with the pupils in English' (concrete).

\section{Procedures}

All participants (student teachers and accountancy students) were thoroughly introduced in the main elements of this study. In each domain (i.e., teacher training and accountancy) a staff member ceded 90 minutes of a lesson to the researcher to familiarise all students with the goals and design of the study, the concept PPT and its qualities, its relevance for vocational education, and the functionalities of the construction module of BrainWeaver®. (They were not familiarised with its use. This was done at the start of each construction session and took only a couple of minutes.) The individual, personal character of a PPT was emphasised; their PPTs had to contain the knowledge, values and convictions they thought useful for practice, not all the knowledge, values and convictions they had learned or 
heard of. Information on their PPTs was confidential and could only be used in their education if they themselves told their supervisors about it. At the end of each session the students were asked whether they were willing to participate voluntarily in the study. (No pressure was applied; waive participation would not harm progress of their education.) Together, the participants formed $82 \%$ of the total population of the third and fourth year of both programs. Students who did not participate gave as a reason that they did not have the time to participate due to other obligations. Each participating student was asked to start thinking about his/her PPT.

For each of the two procedures (C-I and I-C), the two interventions (interviewing a participant and constructing a concept map) were carried out with no more than a few days between them. The CI-participants who produced a concept map first were given an image of their concept map before the interview. If the concept map was constructed after the interview, the participants got a written report of their interview before they drew their concept map. The interviews as a first intervention took an average of 34.7 minutes $(S D=6.5)$, and as a second intervention 26.6 minutes $(S D=5.4)$. The concept maps as first intervention took an average of 51 minutes $(S D=10.4)$, and as a second intervention 43 minutes $(S D=8.5)$.

In each domain, the representations of the interviews and the combined representations were constructed by the researcher. The transcripts of the interviews and the representations were given to two experienced staff members for inspection as to its accuracy and then discussed where necessary. Agreement was reached on all representations. The staff members from teacher education were already familiar with the assessment procedure (Van den Bogaart et al., 2016). Both staff members from accountancy were instructed on and trained in the assessment procedure and the use of the computer program. To obtain sufficient interrater reliability, they each assessed the same three representations, on the four qualities with BrainWeaver®, which yielded high Cohen's Kappa's for richness $(K=.84$, $N=103)$, concreteness $(K=.96, N=45)$, specificity $(K=.90, N=45)$ and complexity $(K=.88$, $N=45)$

Analysis

The first and second research question were answered by means of non-parametric methods. MannWhitney $\mathrm{U}$ tests were used to compare the four qualities of the first representations of accountancy C-I and accountancy I-C. Wilcoxon Signed Rank tests were used to compare the four qualities of the first representations with those of the combined representations. To answer the third research question, the 
eight datasets were united. This provided sufficient numbers to apply a MANOVA-procedure. In this procedure, the qualities of the combined representations were dependent variables and the orders (I-C or C-I), and vocational domains (accountancy or teaching) were independent variables (factors). As additional information on all three research questions, means and standard deviations of the numbers of concepts, relations, theme-sets, relation-sets and domains of knowledge were determined.

\section{Results}

As examples of the kind of data the instrumentation and materials produced, Table 4 shows a theme-set (label: maintaining order) and a relation-set (label: influences). The sets are derived from the interview with the student teacher who constructed the concept map depicted in Figure 1. The interview was held after the map construction (C-I).

*** INSERT TABEL 4 ABOUT HERE ***

The theme-set contains corresponds with the concept maintaining order already contained in the concept map in Figure 1 and adds a new annotation to this concept. The relation-set is new. It represents and annotates a relation between the concepts maintaining order and personal relations with children, which is not contained in Figure 1. The effect is that the concept maintaining order becomes more complex. Figure 3 shows the combined representation of the C-I student teacher of Figure 1. To make a comparison with Figure 1 easier the representation is transformed into a concept map.

\section{*** INSERT FIGURE 3 ABOUT HERE ***}

In comparison with Figure 1, Figure 3 displays two new concepts (i.e., my own development and adaptive education), four new relations connected to these concepts and the new relation described above.

Figure 4 shows the combined representation of the accountancy student who produced the map in Figure 2 transformed into a concept map.

\section{*** INSERT FIGURE 4 ABOUT HERE ***}

The student belongs to the I-C-group. As the interview was taken before the concept map in Figure 2 was constructed, most of the information from the interview was included by the student in the concept map. Only the concepts consolidation and general economics from the interview are missing. ICT was a concept that occurred in the concept map and not in the interview. 
Table 5 displays the mean qualities and standard deviations of the first and the combined representations for the four groups, rounded off to whole numbers.

\section{***INSERT TABLE 5 ABOUT HERE***}

The average number of concepts in the concept maps was $15(S D=3.9)$ and the average number of theme-sets in the interviews was $11.5(S D=2.3)$. The average number of relations in the concept maps was $13.9(S D=4.2)$ and the average number of relation-sets in the interviews was $10.2(S D=4.1)$. While interviews contained anecdotes; concept maps did not. A typical example of a complex, concrete and specific element in a relation-set explaining the relation between more than two concepts (bookkeeping, controlling, and a company's financial situation) is derived from an interview with an accountancy student: "If the books are not correct, then controlling them is superfluous; controlling books is intended to find out if books that seem to be correct at first glance, really represent the financial reality of the company." A typical example of a value statement in an interview with a student teacher is: "I do not think teaching less able children is suited to me. Often keeping order in the classroom prevents me from teaching the subject which I am fond of."

Regarding the first representations of the PPTs of accountancy students, Mann-Witney revealed no significant differences between interviews and concept maps for complexity $(p=.5)$, concreteness $(p=.4)$ or richness $(p=.3)$. Although still not significant, specificity had $p=.07$, twotailed, with a medium effect $(r=.34)$.

Regarding the difference between the first representations and the combined representations, Wilcoxon Signed Rank indicated that the values for complexity, concreteness and specificity differed statistically significant both for accountancy and teaching. The largest $p$ value was found in the group teaching-I-C for specificity: $p=.03$, two-tailed, with a medium effect $(r=.67)$. For the quality richness significant differences were found in both accountancy-C-I $(p=.02, r=.67)$ and accountancy-I-C $(p=.04, r=.51)$. In teaching-I-C and teaching-C-I the differences in richness were not significant: $p=.10$ and $p=.3$.

Before conducting the MANOVA, the data of the combined representations were examined using PASW Statistics to examine if all necessary underlying assumptions were met. Regarding the quality variables, univariate normality was assessed with Shapiro-Wilk-tests and could be assumed, except in case of richness, where significant deviations from univariate normality were found $(p=.02$ for accountancy, $p=.04$ for teaching). No multivariate outliers were found in the data, supporting the 
assumption of multivariate normality. Correlation-analysis showed that multicollinearity was not of concern. Also, the relationships between qualities were roughly linear. Finally, Levene's Test of Equality of Error Variances showed that error variance of the dependent variables could be assumed equal across groups.

The MANOVA showed no significant effects on the combined qualities for both independent variables (profession and order) and their combination; vocational domain (accountancy vs. teaching), order (C-I vs. I-C), combined (domain with order). Analysis of the qualities individually with the independent variable vocational domain, showed no significant effects for each variable.

Finally, the distribution of the domains of knowledge in each of the eight datasets is displayed in Table 6 as additional information.

\section{***INSERT TABLE 6 ABOUT HERE***}

The relative frequencies of Vocational field knowledge in accountancy students are higher than those of the student teachers. The latter referred in relation to this domain of knowledge mainly to the initiative in the Netherlands towards 'inclusive education'; integrating children with learning and/or behavioural problems into regular classes. Accountancy students addressed several developments in their field such as developments in the: accountant's code of conduct, role of the accountant as advisor, tasks of the accountant, and importance of ICT in the profession.

\section{Discussion and Conclusion}

Regarding the first research question, the results support the conclusion that the refined concept map technique supported by BrainWeaver® leads to similar values for all four qualities as compared with interviews in both vocational domains. Although the mean values for concreteness, richness and specificity are somewhat higher in interviews, the differences are not significant. Inspection of the relative frequencies of the domains of knowledge from the first representations for accountancy (see Table 5) showed similar frequencies for concept maps and interviews. On the one hand, the support for the conclusion seems to be modest because of the small sample sizes. On the other hand, the results are similar to those reported by Van den Bogaart et al. (2016) for teacher education, based on a two-year study with 47 participants.

The differences between interviews and concept maps were also visible. The larger average number of concepts compared to the average number of theme-sets derived from interviews is an 
indication for the greater power of concept maps to display the organisation of semantic knowledge. The appearance of anecdotes and value statements in interviews is an indication of the power of interviews to elicit episodic knowledge and values. Finally, some examples have been found in interviews of utterances relating to more than one concept.

Regarding the second research question, the combination of an interview and a concept map clearly led to higher quality values. Although this conclusion is again based on small samples, it is reached in two different domains, with two different techniques and medium effects. Only the results for richness are not unambiguous. In the domain of accountancy the combined representations were significantly richer than the first representation, independent of which technique was used. In the domain of teacher education the differences in richness were not significant. Table 5 shows that the relative frequencies of the domains of knowledge are roughly the same for the first and combined representations in both vocational domains. This indicates that taking both an interview and having the participant construct a concept map does not lead to major changes in the relative importance of the domains of knowledge in participant's PPT.

Regarding the third research question, the MANOVA showed that the order of employing the two techniques did not lead to significant differences in the qualities. Because the assumptions underlying MANOVA were met, with the exception of univariate normality for richness, the result is based on the complete sample of 49 students.

The preceding discussion provides answers to the three research questions: (1) the PPT qualities obtained by the two different techniques (i.e., concept mapping and interviewing) are comparable in both domains, (2) combining the techniques leads to higher quality representations, and (3) the order of using both techniques does not yield different quality representations. Because of the relatively small sample sizes and the limited number of vocational domains, these answers have to be confirmed by more research in different domains of higher vocational education.

The answers are of interest given the importance of PPTs in vocational education as they can provide a foundation for a formative assessment procedure in different vocational domains. Such a procedure should start with the construction of a PPT representation by means of a concept map supported by BrainWeaver®. The answer to the first research question indicates that the determination of the four qualities of this representation is reliable and valid in the accountancy domain also. The results regarding the second research question indicate that despite the comparability, it is worth the 
effort to interview a student about her/his PPT. The answer to the third research question indicates that this can be done after the concept map is constructed, which is highly relevant for educational practice. Carrying out an interview first and then letting a student construct a concept map requires combining the information of both sources in a collection of theme-sets and relation-sets. Such a procedure is laborious and difficult to execute in every day educational practice. This is very different from discussing an analysed concept map with its producer. Because computer-supported construction and analysis of a concept map is relatively easy (Van den Bogaart et al., 2016) and the outcome of the analysis should be discussed with the student anyhow, such a procedure fits well in every day educational practice as part of a formative assessment procedure.

Though there is no experience with the implementation of the procedure yet, taking into account the following aspects is important. (1) The procedure should be performed only after a traineeship, as the processing of practical experience together with theoretical knowledge is fundamental for the development of PPTs (Schaap, Baartman, \& De Bruijn, 2012). (2) There has to be a reasonable amount of time between two measurements of a PPT. Although little is known about the development of PPTs, it seems that they develop slowly (Schaap, Van der Schaaf, \& De Bruijn, 2011). (3) The distinction between espoused theory and theory in use (Jones, Ross, Lynam, Perez, \& Leitch, 2011) is important for the assessments of PPTs. The main objective of PPT assessment is to support professional development. That is why students should be stimulated to explain their own view on the profession, their strengths, their weaknesses and their ambitions, and not what they think their instructor thinks is important (Beijaard, 2009). (4) The ability to explain something by means of a concept map might differ between students (Edmonson, 2000). This might explain some of the differences in quality between PPTs (and also some of the variation in the results of this study).

The results did not reflect any substantial differences between accountancy and teaching. The MANOVA showed $p=.053$ as significance level for the difference in all four qualities taken together between accountancy students and student teachers. As the significance levels for each individual quality are higher, this relative low value expresses the trend that concreteness, specificity and to a lesser extent complexity have higher values for the domain accountancy. As conjectured, this subtle difference could be explained by the stronger procedures in the domain accountancy, which is in sharp contrast with the more chaotic practice of teaching and its twofold knowledge base. Another reason could be that the accountancy students had completed a substantially longer practice period (twenty-six 
weeks) than the student teachers (ten weeks). However, due to the large number of hidden variables that could describe differences within and between these educational programs, further research would be required before such claims could be made.

To obtain more insight into the effects of choice of domain on PPTs, it might be useful to construct a fifth parameter characterising differences in content between representations of PPTs. The four qualities do not measure such differences; two representations can have the same values for complexity, concreteness, specificity and richness and still have different theme-sets and relation-sets. Such a content parameter could be derived from cluster analysis (Johnson \& Wichern, 2002; Trochim \& Cabrera, 2005) and used to measure the diversity of PPTs in a vocational domain as a characteristic of the domain. In the case of accountancy and teaching, this parameter could show stronger differences between domains, than the four discussed qualities do. Moreover, such a parameter could be used to measure the difference in content between the PPTs of two students, or between the PPTs of a student and an expert. Such differences are important when it comes to supporting a student in his/her professional development. An example in the field of teacher education is the difference between the PPT of one student in which the importance of maintaining order in the classroom is expressed as a prominent theme and the PPT of another student which focuses on adapting to the needs of the individual students where the theme of maintaining order is absent (Wubbels \& Brekelmans, 2006). To support both students to become balanced professionals it might be useful to offer them different learning experiences. 


\section{Acknowledgements}

We express our thanks to Peter Hogenhuis, who assisted with the interviews, to Magda Maarleveld, Liesbeth de Ruiter, Ido de Jong and Eenje Ploegman, who carried out the assessments, and to the NHLstudents for participating. 


\section{References}

Ashcraft, M. H. (2006). Cognition (4th ed.). Upper Saddle River, NJ: Pearson Education.

Barriball, K. L., \& While, A. (1994). Collecting data using a semi-structured interview: a discussion paper. Journal of Advanced Nursing, 19, 328-335.

Beijaard, D. (2009). Leraar worden en leraar blijven: over de rol van identiteit in professioneel leren van beginnende docenten [Becoming and staying a teacher: on the role of identity in novice teachers' professional learning]. Inaugural address, Technical University Eindhoven, the Netherlands.

Ben-Peretz, M. (2011). Teacher knowledge: What is it? How do we uncover it? What are its implications for schooling? Teaching and Teacher Education, 27, 3-9.

Bijker, M. M., Van der Klink, M. R., \& Boshuizen, H. P. A. (2010). Success factors of master curricula in business administration during labour market entry. LC: Publications and Preprints. Retrieved from: http://hdl.handle.net/1820/2855.

Buitink, J. (1998). In-functie opleiden en in-functie leren van aanstaande leraren [Training and learning in function of future teachers] (Unpublished doctoral dissertation). UCLO, Groningen, the Netherlands.

Burton, A. M., Shadbolt, N. R., Rugg, G., \& Hedgecock, A. P. (1989). The efficacy of knowledge elicitation techniques: a comparison across domains and levels of expertise. Knowledge Acquisition, 2, 167-178.

Cvetek, S. (2008). Applying chaos theory to lesson planning and delivery. European Journal of teacher Education, 31(3), 247-256.

Edmondson, K. M. (2000). Assessing science understanding through concept maps. In Mintzes, J. J., Wandersee, J. H., \& Novak, J. D. (Eds.). Assessing Science understanding; a human constructivist view (pp. 15-40). Burlington, MA: Elsevier Academic Press.

Elo, S. \& Kyngäs, H. (2008). The qualitative content analysis process. Journal of Advanced Nursing, 62, 107-115.

Furedi, F. (2009). Wasted: why education isn't educating. London, United Kingdom: Continuum International Publishing Group.

Guile, D., \& Griffiths, T. (2001). Learning through work experience. Journal of Education and Work, 14, 113-131. 
Hargreaves, D. H. (2000). The production, mediation and use of professional knowledge among teachers and doctors: a comparative analysis. In Knowledge management in the learning society. Paris, France: OECD Publication Service.

Hines, R. D. (1989). Financial accounting knowledge, conceptual frameworks, projects and the social construction of the accountancy profession. Accounting, Auditing \& Accountability Journal, 2(2), 72-92.

Hsieh, H. F., \& Shannon, S. E. (2005). Three approaches to qualitative content analysis. Qualitative Health Research, 15, 1277-1288.

Jetter, A. (2006). Elicitation - Extracting knowledge from experts. In A. Jetter, H. Schröder, J. Kraaijenbrink, \& F. Wijnhoven (eds.), Knowledge integration: the practice of knowledge management in small and medium enterprises. Heidelberg, Germany: Physica-Verlag HD.

Johnson, R. A., \& Wichern, D. A. (2002). Applied multivariate statistical analysis. Upper Saddle River, NJ: Prentice-Hall Inc.

Jonassen, D. H. (2006). On the role of concepts in learning and instructional design. ETR\&D, 54(2), 177-196.

Jones, N. A., Ross, H., Lynam, T., Perez, P., \& Leitch, A. (2011). Mental models: an interdisciplinary synthesis of theory and methods. Ecology and Society, 16(1), 46-46.

Kolfschoten, G., Lukosch, S., Verbraeck, A., Valentin, E., \& De Vreede, G. J. (2010). Cognitive learning efficiency through the use of design patterns in teaching. Computers \& Education, 54(3), 652-660.

Kondrat, M. E. (1992). Reclaiming the practical: formal and substantive rationality in social work practices. Social Service Review, 66(2), 237-255.

Lave, J., \& Wenger, E. (1991). Situated learning; legitimate peripheral participation. Cambridge: Cambridge University Press.

McCarthy, R. A. (1995). Semantic knowledge and semantic representations: a special issue of Memory. Hove, United Kingdom: Psychology Press.

Milton, N., Clarke, D., \& Shadbolt, N. (2006). Knowledge engineering and psychology: towards a closer relationship. International Journal of Human-Computer Studies, 64, 1214-1229.

Pajares, M. F. (1992). Teachers' beliefs and educational research: cleaning up a messy construct. Review of Educational Research, 62(3), 307-322. 
Pedersen, L. T. (2007). Learning at trade vocational school and learning at work: boundary crossing in apprentices' everyday life. Journal of Education and Work, 20(5), 453-466.

Reif, F. (2010). Applying cognitive science to education: thinking and learning in scientific and other complex domains. Cambridge, MA: The MIT Press.

Ruiz-Primo, M. A., \& Shavelson, R. J. (1996). Problems and issues in the use of concept maps in science assessment. Journal of Research in Science Teaching, 33(6), 569-600.

Schaap, H., Baartman, L., \& De Bruijn, E. (2012). Students' learning processes during school-based learning and workplace learning in vocational education: a review. Vocations and Learning, 5, 99-117.

Schaap, H., De Bruijn, E., Van der Schaaf, M. F., Baartman, L. K. J., \& Kirschner, P. A. (2011). Explicating students' personal professional theories in competence-based vocational education through multi-method triangulation. Scandinavian Journal of Educational Research, 55(6), 567586.

Schaap, H., De Bruijn, E., Van der Schaaf, M. F., \& Kirschner, P. A., (2009). Students' personal professional theories in competence-based vocational education: the construction of personal knowledge through internalisation and socialisation. Journal of Vocational Education and training, 61, 481-494.

Schaap, H., Van der Schaaf, M. F., \& De Bruijn, E. (2011). Development of students' personal professional theories in senior secondary education. Evaluation \& Research in Education, 24(2), 81-103.

Schön, D. A. (1983). The reflective practitioner: how professional think in action. London, United Kingdom: Temple Smith.

Shulman, L. S. (1987). Knowledge and teaching: foundations of the new reform. Harvard Educational Review, 57(1), 1-21.

Ten Dam, G., Van Hout, H., Terlouw, C., \& Willems, J. (2004). Onderwijskunde hoger onderwijs: handboek voor docenten [Theory of higher education: handbook for teachers]. Assen, the Netherlands: Koninklijke van Gorkum.

Tillema, H., \& Smith, K. (2007). Portfolio appraisal: in search of criteria. Teacher and Teacher Education, 23, 442-456. 
Trochim, W. M. K., \& Cabrera, D. (2005). The complexity of concept mapping for policy analysis. $E: C O, 7(1), 11-22$.

Vaatstra, H. F. (1996). Expertise in accountancy. (Doctoral dissertation). Retrieved from pub.maastrichtuniversity.nl/1d9d5ea2-3692-4ad3-af3b-3a776ab88b01.

Van den Bogaart, A. C. M., Bilderbeek, R., Schaap, H., Hummel, H. G. K., \& Kirschner, P. A. (2016). A computer supported method to reveal and assess personal professional theories in vocational education. Technology, Pedagogy and Education. Advance online publication.

Doi.org/10.1080/1475939X.2015.1129986.

Van Driel, J. H., Beijaard, D., \& Verloop, N. (2001). Professional development and reform in science education: The role of teachers' practical knowledge. Journal of Research in Science Teaching, 38(2), 137-158.

Van Oers, B. (1987). Activiteit en Begrip [Activity and understanding] (Doctoral dissertation). Amsterdam, the Netherlands: VU Uitgeverij.

Waks, L. J. (1999). Reflective practice in the design studio and teacher education. Journal of Curriculum Studies, 31(3), 303-316.

Wubbels, T., \& Brekelmans, M. (2006) Two decades of research on teacher-student relationships in class. International Journal of Educational Research, 43, 6-24.

Zanting, A., Verloop, N., \& Vermunt, J. (2003). Using interviews and concept maps to access mentor teachers’ practical knowledge. Higher Education, 46(2), 195-214. 


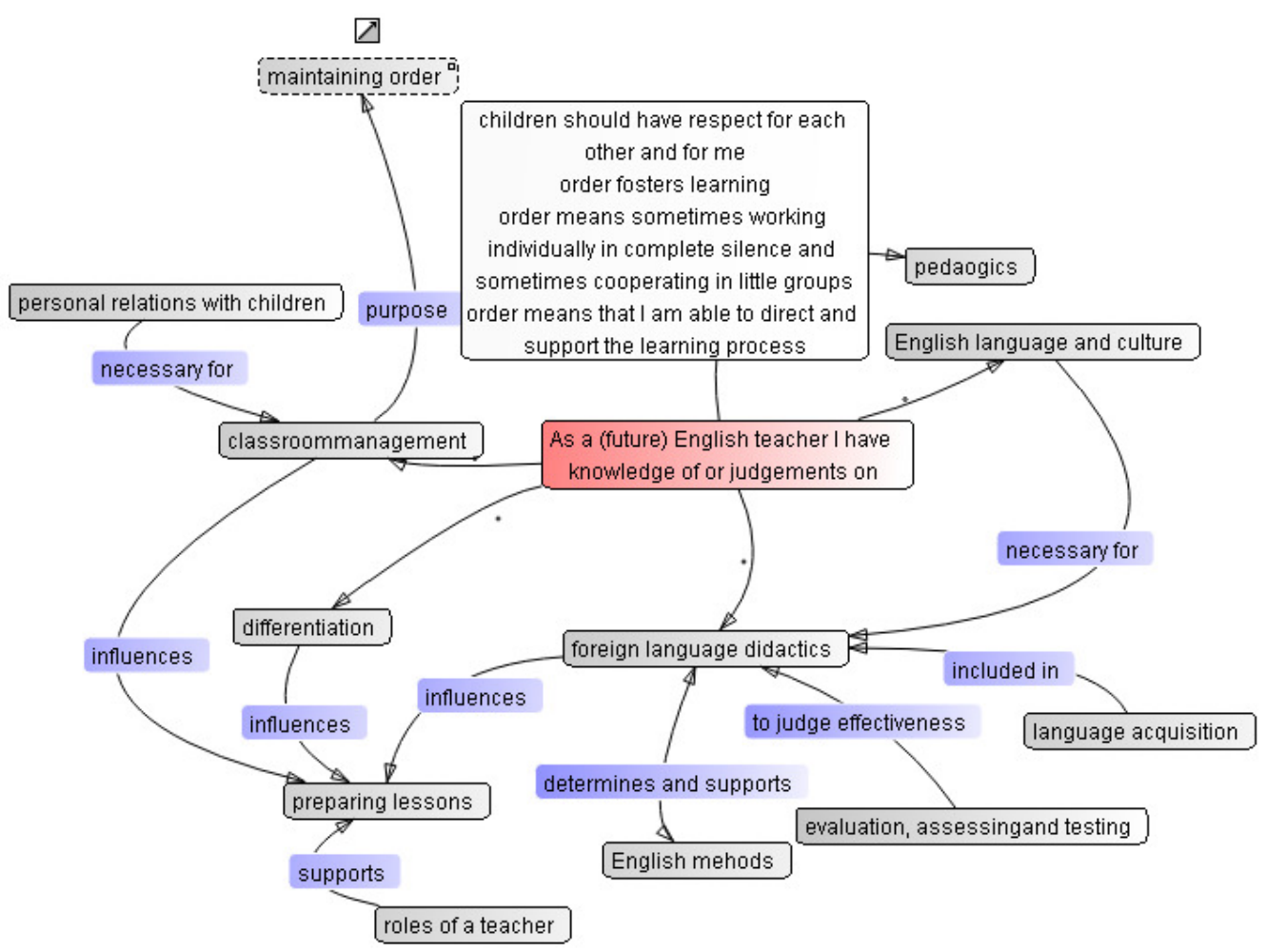

Figure 1. A BrainWeaver ${ }^{\circledR}$ map of the PPT of a student teacher of English 


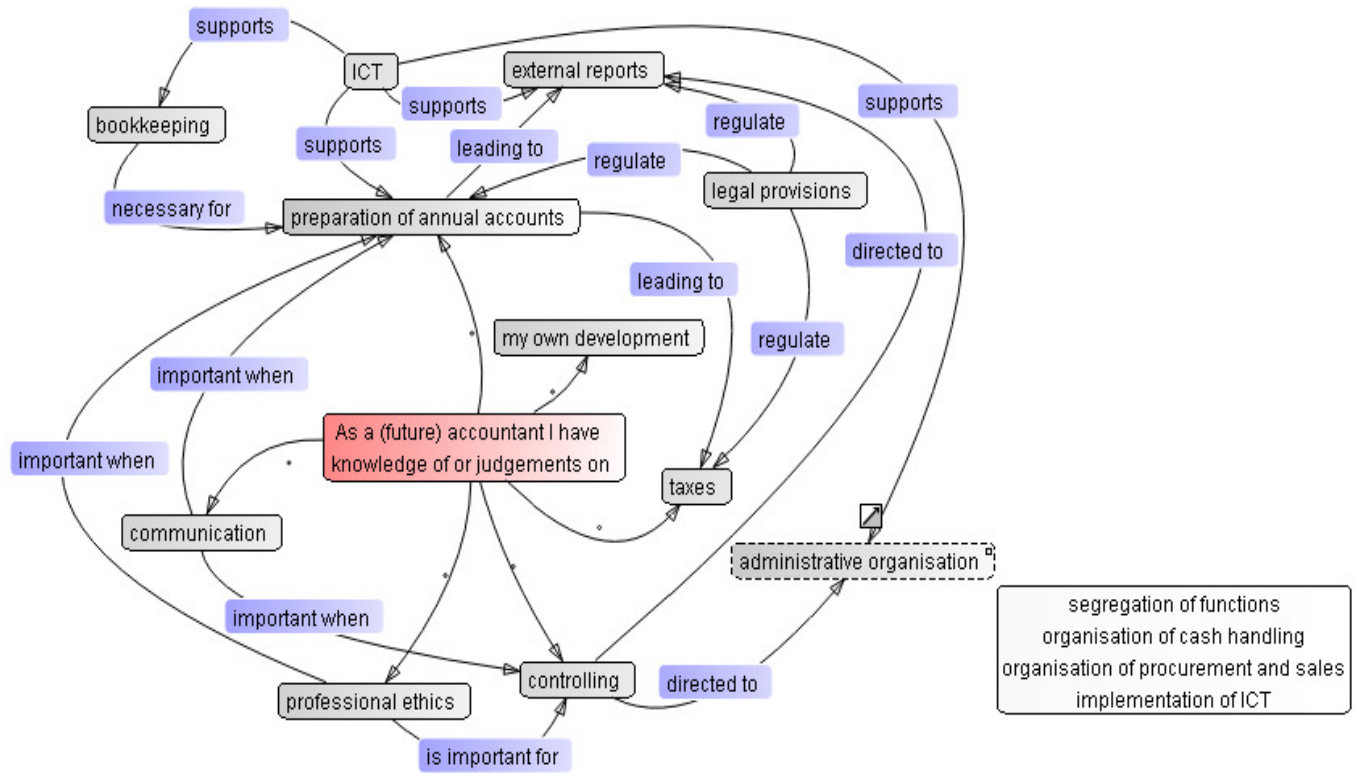

Figure 2. A BrainWeaver ${ }^{\circledR}$ map of the PPT of an accountancy student 


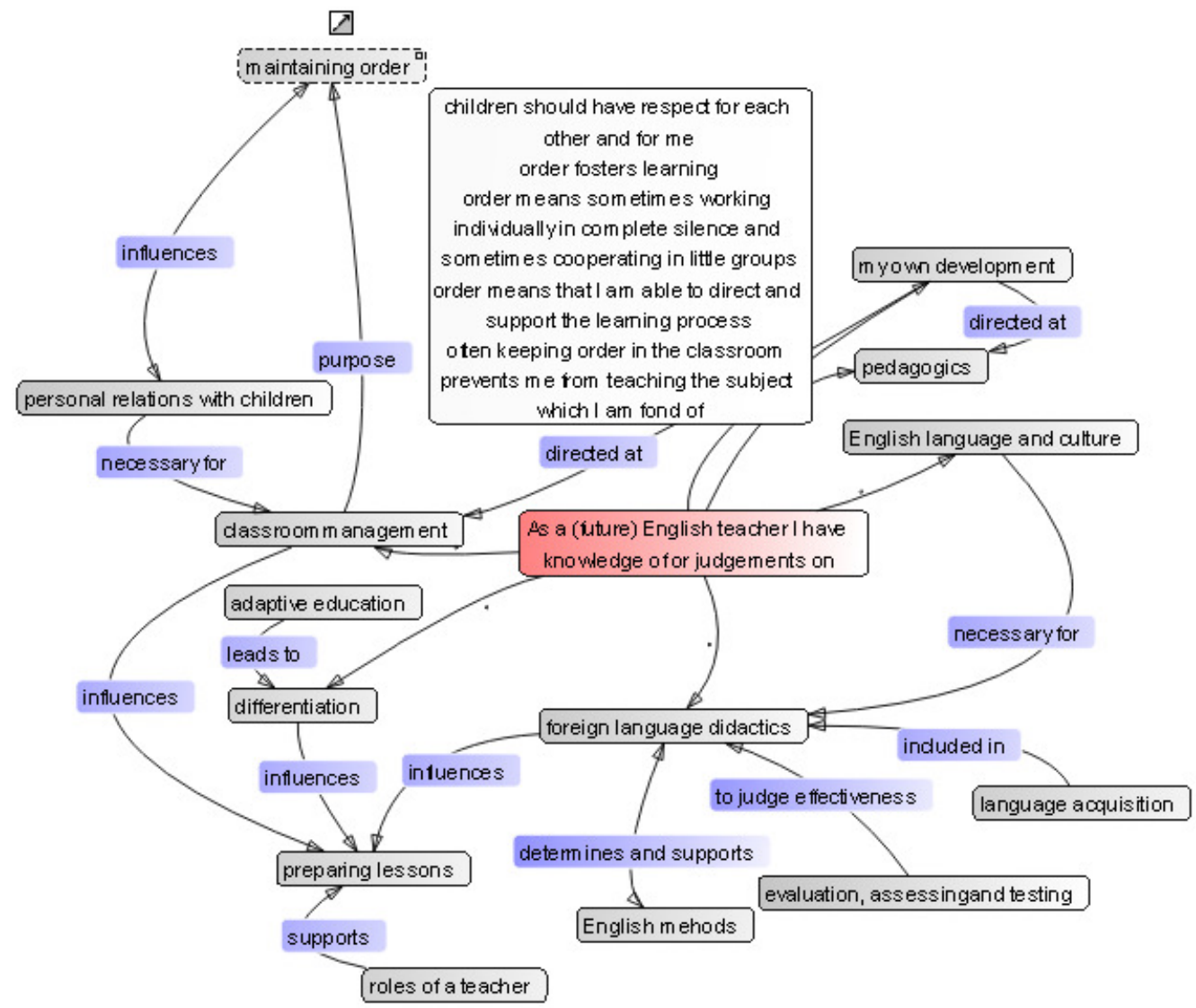

Figure 3. A BrainWeaver ${ }^{\circledR}$ map of the combined representation of the PPT of a student teacher 


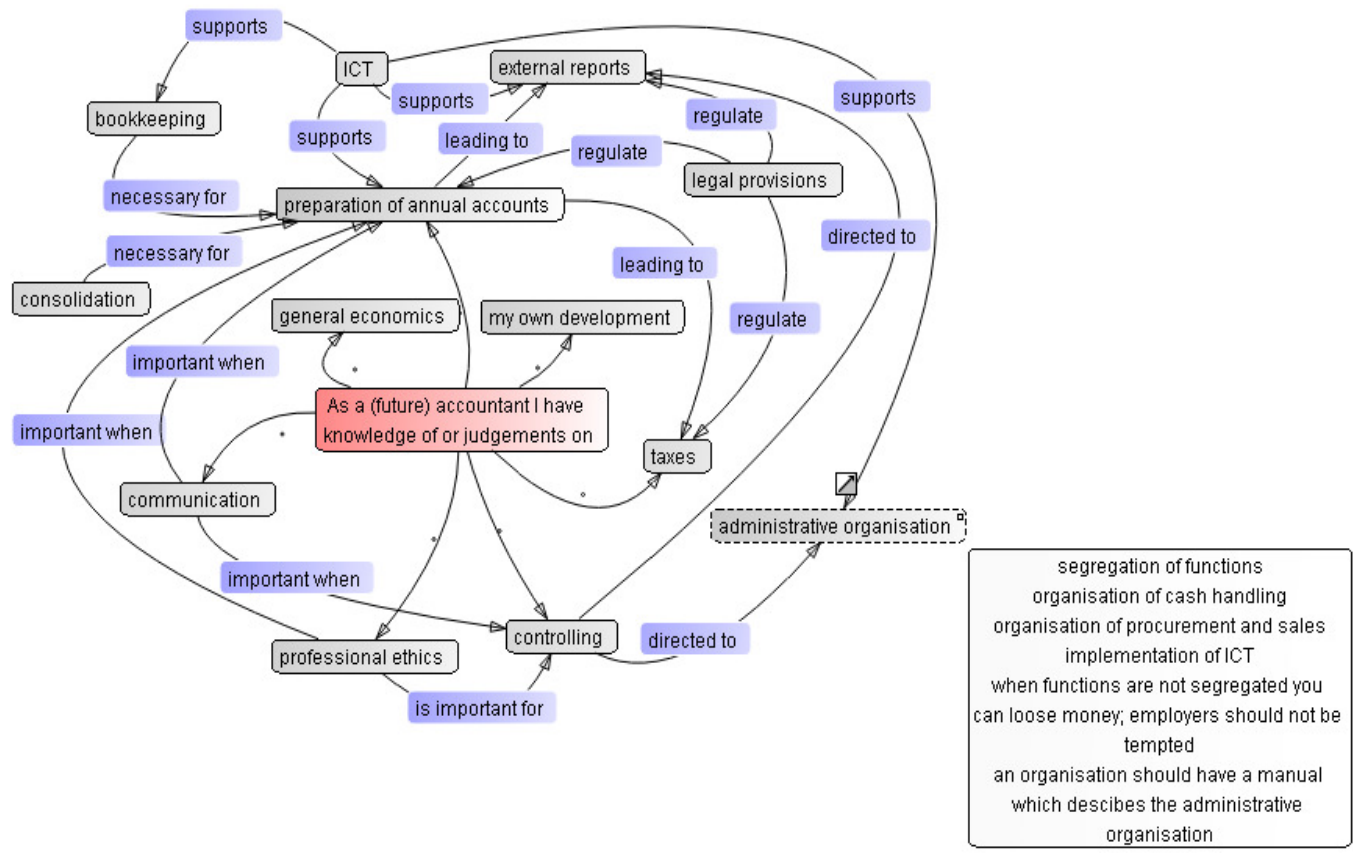

Figure 4. A BrainWeaver® map of the combined representation of the PPT of an accountancy student 
Table 1. Capability of interviews and concept maps to elicit and represent

\begin{tabular}{lcc}
\hline \multicolumn{1}{c}{ Capability to elicit and represent: } & Concept maps & Interviews \\
\hline professional values and beliefs. & - & + \\
\hline encapsulated knowledge. & - & + \\
\hline the organisation of semantic knowledge. & + & - \\
\hline procedural and episodic knowledge & - & + \\
\hline formal and underlying practical knowledge & $+/-$ & $-/+$ \\
\hline
\end{tabular}


Table 2. Assessment of the qualities of the annotations to the concept maintaining order in Figure 1

\begin{tabular}{|c|c|c|}
\hline Annotation & Quality Judgements & Explanation \\
\hline \multirow{3}{*}{$\begin{array}{l}\text { children should have respect } \\
\text { for each other and for me }\end{array}$} & concrete & When there is no respect you have to act. \\
\hline & not specific & Mutual respect is also important outside education. \\
\hline & not complex & No relation between different concepts. \\
\hline \multirow[t]{3}{*}{ order fosters learning } & concrete & When there is no order you have to act. \\
\hline & specific & Proposition is typical for education. \\
\hline & complex & $\begin{array}{l}\text { A relation between two concepts: order and } \\
\text { learning. }\end{array}$ \\
\hline \multirow{4}{*}{$\begin{array}{l}\text { order means sometimes } \\
\text { working individually in } \\
\text { complete silence and } \\
\text { sometimes cooperating in } \\
\text { little groups }\end{array}$} & concrete & When there is no complete silence working \\
\hline & & $\begin{array}{l}\text { individually or when there is no cooperation, you } \\
\text { have to act. }\end{array}$ \\
\hline & specific & Proposition is typical for education. \\
\hline & not complex & No relation between different concepts. \\
\hline \multirow{3}{*}{$\begin{array}{l}\text { order means that I am able } \\
\text { to direct and support the } \\
\text { learning process }\end{array}$} & concrete & $\begin{array}{l}\text { When it is impossible to direct learning processes } \\
\text { you have to act. }\end{array}$ \\
\hline & specific & Proposition is typical for education. \\
\hline & complex & $\begin{array}{l}\text { A relation between two concepts: order and } \\
\text { learning processes. }\end{array}$ \\
\hline
\end{tabular}


Table 3. Assessment of the annotations to the concept administrative organisation in Figure 2

\begin{tabular}{|c|c|c|}
\hline Annotation & Quality Judgements & Explanation \\
\hline \multirow[t]{3}{*}{ segregation of functions } & concrete & $\begin{array}{l}\text { An accountant acts (i.e., informs management) if } \\
\text { (important) functions are not segregated }\end{array}$ \\
\hline & specific & Typical organisational focus of accountants \\
\hline & not complex & No relation between different concepts \\
\hline \multirow[t]{3}{*}{$\begin{array}{l}\text { organisation of cash } \\
\text { handling }\end{array}$} & concrete & $\begin{array}{l}\text { An accountant informs management if cash } \\
\text { handling is not organised according to standards }\end{array}$ \\
\hline & specific & Typical administrative focus of accountants \\
\hline & not complex & No relation between different concepts \\
\hline \multirow[t]{3}{*}{$\begin{array}{l}\text { organisation of procurement } \\
\text { and sales }\end{array}$} & concrete & $\begin{array}{l}\text { An accountant informs management if procurement } \\
\text { and sales is not organised according to standards }\end{array}$ \\
\hline & specific & Typical organisational focus of accountants \\
\hline & not complex & No relation between different concepts \\
\hline \multirow[t]{3}{*}{ implementation of ICT } & concrete & $\begin{array}{l}\text { An accountant informs management if the software } \\
\text { a firm uses is not implemented according to } \\
\text { standards }\end{array}$ \\
\hline & specific & Typical organisational focus of accountants \\
\hline & not complex & No relation between different concepts \\
\hline
\end{tabular}


Table 4. A theme-set and a relation-set related to Figure 1

\begin{tabular}{lll}
\hline $\begin{array}{l}\text { Maintaining order } \\
\text { (Theme-set) }\end{array}$ & $\begin{array}{l}\text { Often keeping order in the classroom prevents me from teaching the subject } \\
\text { which I am fond of. }\end{array}$ \\
\hline $\begin{array}{l}\text { Maintaining order and } \\
\text { personal relations with } \\
\text { children influence each }\end{array}$ & $\begin{array}{l}\text { - } \\
\text { other }\end{array}$ & When children like you they are more likely to behave in such a way that you \\
(Relation-set) & can work with them. \\
& they ultimately want to learn something. \\
& In general children do not like teachers who cannot maintain order in their \\
& classes
\end{tabular}


Table 5. The qualities of the first and combined representations

\begin{tabular}{|c|c|c|c|c|c|c|c|c|}
\hline & \multicolumn{2}{|c|}{ Accountancy-C-I } & \multicolumn{2}{|c|}{ Accountancy-I-C } & \multicolumn{2}{|c|}{ Teaching-C-I } & \multicolumn{2}{|c|}{ Teaching-I-C } \\
\hline & first & comb. & first & comb. & first & comb. & first & comb. \\
\hline & $M(S D)$ & $M(S D)$ & $M(S D)$ & $M(S D)$ & $M(S D)$ & $M(S D)$ & $M(S D)$ & $M(S D)$ \\
\hline Complexity & $33(17)$ & $45(15)$ & $32(14)$ & $50(16)$ & $32(15)$ & $37(14)$ & $33(14)$ & 47 (14.) \\
\hline Concreteness & $54(29)$ & $72(15)$ & $63(16)$ & $74(15)$ & $51(17)$ & $67(16)$ & $58(9)$ & $67(15)$ \\
\hline Specificity & $45(27)$ & $60(17)$ & $59(18)$ & $68(14)$ & $45(13)$ & $63(10)$ & $57(9)$ & $66(15)$ \\
\hline Richness & $37(17)$ & $47(12)$ & $44(10)$ & $48(12)$ & $40(11)$ & $43(9)$ & $44(5)$ & $48(11)$ \\
\hline
\end{tabular}


Table 6. The relative frequencies of the domains of knowledge

\begin{tabular}{|c|c|c|c|c|c|c|c|c|}
\hline & \multicolumn{2}{|c|}{ Accountancy-C-I } & \multicolumn{2}{|c|}{ Accountancy-I-C } & \multicolumn{2}{|c|}{ Teaching-C-I } & \multicolumn{2}{|c|}{ Teaching-C-I } \\
\hline & first & comb. & first & comb. & first & comb. & first & comb. \\
\hline & $M(S D)$ & $M(S D)$ & $M(S D)$ & $M(S D)$ & $M(S D)$ & $M(S D)$ & $M(S D)$ & $M(S D)$ \\
\hline $\begin{array}{c}\text { Vocational field } \\
\text { knowledge }\end{array}$ & $12(9)$ & $12(6)$ & $13(10)$ & $13(6)$ & $1(1)$ & $1(2)$ & $1(3)$ & $2(3)$ \\
\hline Organisations & $1(2)$ & $2(3)$ & $2(6)$ & $2(4)$ & $3(6)$ & $2(5)$ & $6(5)$ & $5(4)$ \\
\hline $\begin{array}{l}\text { Professional } \\
\text { environment }\end{array}$ & $0(1)$ & $0(1)$ & $1(3)$ & $1(2)$ & $1(3)$ & $1(2)$ & $1(2)$ & $1(1)$ \\
\hline Target group & $8(10)$ & $6(6)$ & $8(7)$ & $6(5)$ & $15(6)$ & $14(5)$ & $22(9)$ & $20(8)$ \\
\hline $\begin{array}{l}\text { Technical- } \\
\text { instrumental }\end{array}$ & $73(19)$ & $68(14)$ & $71(11)$ & $66(12)$ & $78(9)$ & $70(8)$ & $65(13)$ & $63(15)$ \\
\hline Self-knowledge & $3(7)$ & $11(6)$ & $5(6)$ & $12(6)$ & $2(3)$ & $10(7)$ & $6(6)$ & $9(6)$ \\
\hline
\end{tabular}

